\title{
Innovation and growth ambition of female entrepreneurs: a comparison between the MENA region and the rest of the world
}

\section{Mehrzad Saeedikiya*}

Faculty of Political, Economic and Social Sciences,

University of Milan,

Milan, Italy

Email: mehrzad.saeedikiya@studenti.unimi.it

*Corresponding author

\section{Zeynab Aeeni}

Faculty of Entrepreneurship,

University of Tehran,

Tehran, Iran

Email: aeeni.1365@ut.ac.ir

\begin{abstract}
The aim of the current paper was to compare the regional differences in innovation and the resulting growth expectation among female entrepreneurs in the MENA region as compared with the rest of the world. Data on innovation and growth aspirations of 162,752 female entrepreneurs in 109 countries was extracted from GEM annual surveys in 2002-2016. A hierarchical linear modelling technique was used to analyse the data. Interestingly, results indicated that female entrepreneurs in the MENA region are more innovative than their peers in the rest of the world; however, there is no difference between the MENA female entrepreneurs and their counterparts in the rest of the world in terms of growth ambitions and benefiting from innovation for growth. Innovation was found to be positively related to shaping growth ambitions in female entrepreneurs.
\end{abstract}

Keywords: female entrepreneurs; MENA region; innovation; growth expectation.

Reference to this paper should be made as follows: Saeedikiya, M. and Aeeni, Z. (2020) 'Innovation and growth ambition of female entrepreneurs: a comparison between the MENA region and the rest of the world', MENA J. Cross-Cultural Management, Vol. 1, No. 1, pp.7-19.

Biographical notes: Mehrzad Saeedikiya is an early career researcher of entrepreneurship at University of Milan, Italy. He has held other research positions at Tsinghua University in China and University of Tehran, Iran.

Zeynab Aeeni holds a PhD in Entrepreneurship from University of Tehran and currently holds a Lecturer position at University of Kurdestan, Iran. He has played different teaching and research roles at University of Tehran. 


\section{Introduction}

Given the lower rate of female entrepreneurial activities in the Middle East and North Africa (MENA) and the greatest gender disparity in this area as compared with the developed world (Hill and Akhrass, 2018), it is necessary to study women entrepreneurial activities in the MENA region (Bastian et al., 2018). The performance of women-owned firms is one of the under-explored topics. Growth can be an appropriate indicator for evaluating female-owned business performance (Filculescu, 2016) because represents the degree of entrepreneur's success (Gartner and Liao, 2012). However, entrepreneurs can decide whether they want their business to grow or not. Hence, a key predictor of actual business growth is the entrepreneur's growth ambition.

Considering the role of growth motivation in predicting business growth, extensive research has been conducted on the determinant factors affecting entrepreneur's growth expectation in three levels of analysis, including individual, business, and environmental level (Saeedikiya et al., 2017). There is a paucity of research on the relationship between business' innovative activities and growth expectation (Castaño et al., 2016), specifically among female entrepreneurs. Given the criticality of the role of socioeconomic context on female entrepreneur's growth expectation (Davidsson et al., 2010), an underexplored question arises: how female entrepreneurs' growth expectation under the moderating influence of context benefit from innovation?

The literature on growth expectation among female entrepreneurs is expanding and many scholars evaluate gender variable in their studies. However, the majority of studies in this field have investigated the differences between male and female entrepreneurs (Brixiová and Kangoye, 2016) with a major focus on developed Anglo-Saxon countries, or challenging environments in Eastern Europe, or Latin America. A better understanding of female entrepreneur's growth expectation requires exploring the dimensions of female entrepreneurship in other under-explored contexts such as the MENA region (Sadeq and Setti, 2013; Bastian et al., 2018). It should be noted that studying women entrepreneur's growth ambition and performance in the MENA region not only has its own advantages, but also conducting comparative studies have the potential to explain this phenomenon more comprehensively (Bastian et al., 2018). Accordingly, the current study compares the level of innovation, growth expectation, and benefits of innovation for growth among female entrepreneurs in the MENA region, as compared with their counterparts in the rest of the world. In other word, the authors seek to answer the following questions: Is there any difference in innovation and growth ambition of female entrepreneurs in the MENA region as compared with the female entrepreneurs in the rest of the world? Is the benefit of innovation for growth is different among female entrepreneurs in the MENA region as compared with their counterparts in the rest of the world?

The remainder of this paper is organised in different parts: first, the authors review the relevant literature on female entrepreneurs' innovation and growth with a special focus on the MENA region. Then, we present the methodology with details on sample, operationalisation of the variables, and statistical analyses. Finally, the results will be presented and discussed in order to provide some suggestions for future research and the potential areas needing further and more accurate inquiry. 


\section{Theoretical backgrounds and hypotheses}

Entrepreneurs can decide whether to grow their firm or not (Sadeq and Setti, 2013). Therefore, growth ambition is one of the key predictors of actual firm growth (Bulanova et al., 2016). Therefore, understanding the entrepreneur's growth expectation can be considered as an initial stage to explain actual business growth (Bulanova et al., 2016). Hence a critical topic for the entrepreneurship literature is to explore the factors affecting entrepreneurial growth expectation, which in turn can result in actual firm growth. In the following parts, the authors provide a comparative regional insight on growth expectations, innovation, and benefit of innovation for growth among female entrepreneurs in the MENA region as compared with their counterparts in the rest of the world.

\subsection{Innovation affecting growth expectations in female entrepreneurs}

Several mechanisms can be used to explain the effect of innovation on growth expectations of entrepreneurs: marketing approach, strategic management approach, and economic approach. Using a strategic management approach, one can refer to the resource-based view according to which innovation can be considered as a source of value, scarcity, complexity, and non-substitutivity (Roxas and Chadee, 2011) which brings competitive advantage for firms existing in a market (Saeedikiya et al., 2017). In a similar vein, innovation can be understood as a source of price competition (Porter, 2008). In a marketing approach, innovations help to attract more loyal customers or protects firms against market entry barriers (Claude-Gaudillat and Quélin, 2006). Using an economic approach, one also can argue that innovation can be a source of economies of scale and economies of scope. In this sense, entrepreneurs who benefit from price competitiveness and product diversifications increase the likelihood of success and thus, shape more growth ambitions. These theoretical views have gained support in the empirical setting. A study by Saeedikiya et al. (2017) showed that entrepreneurs who are more innovative are prone to shape more growth expectations. Castaño et al. (2016) have found that technological innovation increases the likelihood of internationalisation and positively influences entrepreneurs' growth expectation. Building on above arguments, the authors hypothesised that:

Hypothesis 1 Innovation affects growth ambitions of female entrepreneurs positively.

\subsection{Innovation and growth expectation of female entrepreneurs in the MENA region}

The growth expectation seems to vary significantly, depending on the socioeconomic context in which entrepreneurs run their business. Different contexts may be indicative of different structures of entrepreneurship drivers and barriers (Aeeni et al., 2019). In the MENA region, the rate of the participation of women in entrepreneurship is not only lower than male counterparts but also lower than female entrepreneurs in the rest of the world (Bahramitash and Esfahani, 2016). To gain a deeper insight on female entrepreneurship and understanding gender differences in their entrepreneurial performance specifically in MENA region, these limitations can be classified into five important themes: 
The first theme is the level of human capital. Entrepreneur's skills, experience, and education are totally known as human capital. Entrepreneur's human capital is directly and positively associated with growth expectation (Manolova et al., 2007). Women business owners often lack prior business experience, especially in managerial positions (Poggesi et al., 2016). Lack of managerial skills (Welsh et al., 2014), limited access to training (Zeidan and Bahrami, 2011), or lack of skilled workers (Bahramitash and Esfahani, 2016) are some key human capital constraints faced by female entrepreneurs in the MENA region.

The second theme is the access to financial capital. Access to finance is a key driver in the creation, survival and growth of new innovative ventures. More constraints in accessing capital results in more challenges in opening and expanding a business by females (Brixiová and Kangoye, 2016). Female-owned business in the MENA region have limited access to financial capital, especially in the formal sector (Idem). Research evidence shows that socio-cultural context has a significant limiting effect on women potential to access key resources especially financial capital. For example, in some countries in the MENA region some dominant religious beliefs and traditions provide men with a significant authority over women in terms of financial responsibility (Kazemi, 2000) which limits women's access to critical financial resources and confines their ability to start and develop their own business (Bastian et al., 2018).

The third theme is networking. Social capital increases entrepreneur's access to appropriate resources from their networks and play a significant role in reinforcing growth expectation (Liao and Welsch, 2003). Research shows that networking activities of female entrepreneurs are different from those of males. Manolova et al. (2007) found that networking has a more significant effect on female growth expectations than males. However, nature and structure of networks are very important. Networking in private sphere and close acquaintances have less potential to motivate growth expectation than networking in public sphere (Sadeq and Setti, 2013). As compared with the formal and heterogeneous nature of males' social networks, females significantly resort to informal and homogenous networks (Bahramitash and Esfahani, 2016), which is due to women's limitation in accessing formal and extensive networks. This limitation is more significant in female-entrepreneurs in the MENA region. Women's networking behaviours in the MENA region is influenced by cultural values; accordingly, they are expected to be almost connected with family and close friends (Ahmad, 2011). There are several formal and informal prescriptions that prohibit or discourage women from interacting with men other than their own relatives or to venture outside family borders. Hence, they need to have male permission for conducting business activities or almost always a male intermediary on behalf of them undertakes these affairs (Welsh et al., 2014). Sometimes, the lack of these male agents can endanger female ventures. Such norms and values can negatively influence female entrepreneur' networking, though there are diverse and heterogeneous actors in the market.

The fourth theme is work-family balance. Female entrepreneurs' obligation to meet their home responsibilities other than business activities such as housework tasks can discourage their growth-related decisions. Responsibilities traditionally assigned to woman such as caring for children are the major constraints hindering the growth of female-owned business. Although work-family balance is a major challenge for female entrepreneurs all around the world (Bastian et al., 2018), it is a stranger restrictive factor in the MENA region; accordingly, female entrepreneurs are more restricted by the society's stereotypes about their social roles and their gender identity. To put emphasise 
on the topic, entrepreneur' gender identity or the extent to which entrepreneurs possess traits associated with traditional gender stereotypes is an important predictor of growth expectation in both males and females (Zampetakis et al., 2016). In the MENA region, cultural norms and values define women identity based on their role as a wife, mother, or caregiver at home (Tlaiss and Kauser, 2011) and this can make some conflicts regarding their entrepreneurial ambitions (such as growth ambitions) and entrepreneurial activities.

The fifth theme is entrepreneurial confidence. Research have found that in general female entrepreneurs are more risk averse than males (Watson, 2012). This feature is more significant among female entrepreneurs in the MENA region, because in this region, communities are characterised by patriarchal values which means that men are viewed as decisive and powerful bodies, and women are dependent and under the men's influence (Ahmad, 2011). As a consequence, women lack sufficient confidence about their entrepreneurial potential (Belwal et al., 2014). Indeed, this can be magnified by the fear of failure (Poggesi et al., 2016) which has negative effects on taking risk toward innovation.

These restrictive themes can cause female entrepreneurs to underperform in some areas of entrepreneurship. The institutional inefficiencies of MENA region also can magnify this underperformance and cause the female entrepreneurs in the MENA region to innovate less and be less ambitious about their business growth as compared with their counterparts in the rest of the world. Therefore, the second and the third hypotheses are formulated as follows:

Hypothesis 2 As compared with their peers in the rest of the world, female entrepreneurs in the MENA region are less ambitious for growth.

Hypothesis 3 Female entrepreneurs in the MENA region are less innovative than their counterparts in the rest of the world.

\subsection{Effect of innovation on growth expectation moderated by region}

Apart from expecting lower levels of growth in female entrepreneurs in the MENA region, there are some evidences suggesting that female entrepreneurs in this region shape less growth aspirations on the basis of their innovation. To explain this, we use the institutional hierarchy of Williamson (2000) that considers the embeddedness of economic activity in four levels of analysis. The first level is the informal institutions level based on which, norms, customs and belief system can influence economic activity. For Williamson (2000), the first level presents social embeddedness level in which economic activity is embedded in the value system of communities. Hence, there is a cultural element for female entrepreneurs in the MENA region who mostly live within a cultural system that values subsistence and survival rather than human aspirations (Inglehart and Welzel, 2010). In this sense, one can conclude that female entrepreneurs in the MENA region expect less growth from their innovation, as compared with women in communities with more self-expressive values. Moving to the Williamson's (2000) second level of hierarchy, there are formal rules of the game. Considering this level in the MENA region, one can understand the presence of too many regulative and constitutive limitations in the MENA region impeding growth potential of entrepreneurs from their innovation. The high level of corruption, weak intellectual property system, and weak legal system are more evident in under-developed contexts such as the MENA region, as 
compared with other regions. In other words, these regulatory institutions are not efficient enough to promote productive entrepreneurship (Aeeni et al., 2019). Moving to the third level of the Williamsons' (2000) hierarchy, there is the governance level in which, the governance of contractual relations becomes the focus of analysis and determines the way that individuals interact. Applying this level to the MENA region, there are some limitations in terms of social interactions and networking patterns adopted by entrepreneurs in the MENA region which can be characterised as homogenous and bounded in family relationships. Some authors have shown that the homogenous nature of female entrepreneur's social network is negatively related to opportunity identification and innovation (Renzulli et al., 2000). This, in turn, can prevent women from taking risky decisions and result in opportunities for innovation. These characteristics can lower the level of innovation and consequently benefit for growth among female entrepreneurs in the MENA region, as compared with their counterparts in more developed countries. The fourth level is the resource allocation level affected by the former three levels. At this level, actual decisions about innovation and growth ambitions can be shaped by the influencers from the three higher levels. Referring back to Williamson's framework, the authors argue that female entrepreneurs in the MENA region are less ambitious about the growth out of their innovation, as compared with their counterparts in the world. This argument is rooted in the fact that in each level of Williamson's hierarchy, huge normative, regulative, legislative, and institutional inefficiencies exist and these inefficiencies can limit the benefit of innovation for growth non-female entrepreneurs in the MENA region. Based on the above arguments, the authors hypothesised that:

Hypothesis 4 Female entrepreneurs in the MENA region expect less growth from their innovation as compared with their peers in the rest of the world.

\section{Methodology}

\subsection{Data and sampling}

The current research benefits from data collected by Global Entrepreneurship Monitor. By its Adult Population Survey (APS), GEM measures firm innovation and growth expectations of the entrepreneurs. Our data was extracted from a sample of 109 countries participated in GEM annual surveys in 2002-2016 and this yields a sample of roughly 162,752 female entrepreneurs. The countries participate in GEM surveys by self-selection annually. In the current research the data of the following the MENA countries has been extracted and coded for further analysis: UAE, Angola, Cameroon, Botswana, Algeria, Egypt, Ethiopia, Ghana, Jordan, Iran, Israel, Kuwait, Libya, Morocco, Malawi, Namibia, Nigeria, Palestine, Qatar, Saudi Arabia, Senegal, Syria, Tunisia, Tonga, Turkey, Uganda, Yemen, South Africa, and Zambia. The data of the MENA region has been compared to data of 77 other countries around the globe.

\subsection{Measuring research variables}

\subsubsection{Growth expectation}

The firm growth expectation, was calculated by measuring the expected growth in employment in the next five years which will be calculated using the following formula: 
Employment growth expectation $=\mathrm{LN}$ (number of employees in the next five years +1 ) $-\mathrm{LN}$ (number of employees in the time of survey +1 ).

\subsubsection{Innovation}

Three components of innovation namely, product innovation, process innovation and perceived competition have been measured by GEM APS. The three components have been measured in APS by asking the following questions for product innovation, process innovation and competition respectively:

- Product innovation: Do all, some, or none of your potential customers consider this product or service new and unfamiliar? Respondents rate product innovation within their firm based on a three-point scale from 1 to 3 (3 denotes the highest level).

- Process innovation: Have the technologies or procedures required for this product or service been available for less than a year, or between one to five years, or longer than five years? Respondents rate the level of process innovation within their firms on a three-point scale ranging from 1 to 3 (3 denotes the highest level).

- Competition: Right now, are there many, few, or no other businesses offering the same products or services to your potential customers? Participants report their perceived degree of competitiveness on a three-point scale from 1 to 3 , with 1 denotes the highest level of innovation and 3 denotes the lowest level. In the current paper, the mean of these variables was used as a single index of innovation.

\subsubsection{Region}

Coded 1 for the MENA countries and 0 for the countries in the rest of the world.

\subsubsection{Control variables}

- $\quad$ Age of the entrepreneurs: Logarithm of the age.

- Self-efficacy: Dichotomous variable coded 1 for self-efficacious and 0 for non-self-efficacious.

- Risk-willingness: Dichotomous variable coded 1 for risk-willing and 0 for fearing.

- Education: The level of entrepreneurs' education, standardised score.

- Firm age: Logarithm of the number of years plus one.

- Firm size Logarithm of the number of employees plus the owner/managers.

- $\quad$ Role modelling opportunity: Dichotomous variable coded 1 if having a role model and 0 if not.

- Opportunity alertness: Dichotomous variable coded 1 if being alert and 0 if not.

- Extractive sector: Dichotomous variable coded 1 if operating in extractive sector and 0 if not.

- Business services sector: Dichotomous variable coded 1 if operating in business services sector and 0 if not. 
- $\quad$ Transforming sector: Dichotomous variable coded 1 if operating in transforming sector and 0 if not.

- Customer oriented sector: Dichotomous variable coded 1 if operating in customeroriented sector and 0 if not.

- GNI: Logarithm of GNI.

\subsection{Statistical analysis}

Since the current study uses the data in different levels of analysis (country level and the firm level), hierarchical linear modelling (HLM) is more appropriate than linear regression. Applying HLM while testing the direct effects, has the advantage of controlling for the effects of other variables which may affect the results.

\section{Results}

In this section, first, a description of the sample along with correlation coefficient of the variables has been reported. Then, the results of hypotheses testing have been provided. Table 1 shows the results of correlation analysis between variables of interest in the current research.

Table 1 Correlation coefficients between variables of the study

\begin{tabular}{lccccc}
\hline & Mean & Std. & Innovation & Growth & Region \\
\hline Innovation & 1.5 & 0.5 & 1 & $0.065^{* *}$ & $0.073^{* *}$ \\
Growth expectation & 0.8 & 2.36 & $0.065^{* *}$ & 1 & $0.037^{* *}$ \\
Region & 0.19 & 0.4 & $0.073^{* *}$ & $0.037^{* *}$ & 1 \\
Self-efficacy & 0.81 & 0.39 & $0.041^{* *}$ & $0.025^{* *}$ & -0.003 \\
Age & 34 & 11.5 & $-0.085^{* *}$ & $-0.073^{* *}$ & $-0.075^{* *}$ \\
Role modelling & 0.56 & 0.496 & $0.072^{* *}$ & $0.024^{* *}$ & $0.014^{* *}$ \\
Education & 11.22 & 3.78 & $0.083^{* *}$ & $0.013^{* *}$ & $0.013^{* *}$ \\
Risk-willingness & 0.70 & 0.46 & $0.032^{* *}$ & $0.019^{* *}$ & $-0.01^{* *}$ \\
Opportunity alertness & 0.56 & 0.49 & $0.085^{* *}$ & $0.046^{* *}$ & $0.006^{*}$ \\
Log firm age & 1.03 & 1.1 & $-0.15^{* *}$ & $-0.05^{* *}$ & $-0.035^{* *}$ \\
Log firm size & 1.5 & 2.0 & $0.05^{* *}$ & $-0.28^{* *}$ & $0.012^{* *}$ \\
Extractive sector & 0.5 & 0.22 & $-0.07^{* *}$ & $-0.024^{* *}$ & $-0.028^{* *}$ \\
Transforming sector & 0.13 & 0.34 & $0.010^{* *}$ & $0.012^{* *}$ & $0.015^{* *}$ \\
Business services sector & 0.10 & 0.30 & $-0.015^{* *}$ & $-0.01^{* *}$ & $-0.017^{* *}$ \\
Customer oriented sector & 0.45 & 0.50 & $0.019^{* *}$ & $0.01^{* *}$ & $-0.047^{* *}$ \\
GNI LOG & 2.48 & 1 & 0.00 & $-0.043^{* *}$ & $-0.032^{* *}$ \\
\hline
\end{tabular}

Notes: ${ }^{\text {aMiddle East }}=1$ and rest of the world $=0$.

*significant at $\mathrm{p}<0.05 ; * *$ significant at $\mathrm{p}<0.01$. 


\section{Results of hypotheses testing}

Table 2 gives information on the effect of innovation and region on growth. Hypothesis 1 hypothesised that innovation has a positive effect on growth expectations of the female entrepreneurs. This hypothesis is supported by the results $(\beta=0.04, p$-value $<0.05)$. In other words, female entrepreneurs who innovate more, expect more employment growth in their firm in the next five years than those who are less innovative.

Hypothesis 2 predicted less growth expectations for female entrepreneurs in the MENA region as compared to the rest of the world. Results indicated that growth expectation of female entrepreneurs in the MENA region is not significantly different than that of female entrepreneurs in the rest of the world.

Table 2 Growth expectation affected by innovation and region

\begin{tabular}{|c|c|c|}
\hline & Model 1 & Model 2 \\
\hline Innovation & $0.04 * *$ & $0.02 *$ \\
\hline Region $^{\mathrm{a}}$ & -0.21 & 0.07 \\
\hline Innovation $*$ region & & -0.13 \\
\hline Self-efficacy & 0.01 & 0.01 \\
\hline Age & 0.00 & 0.00 \\
\hline Role modelling opportunity & 0.02 & 0.02 \\
\hline Education & 0.01 & 0.01 \\
\hline Risk-willingness & $0.05 * *$ & $0.05 * *$ \\
\hline Opportunity alertness & -0.02 & -0.02 \\
\hline Log firm age & $-0.02 * *$ & $-0.02 * *$ \\
\hline Log firm size & $-0.27 * *$ & $-0.27 * *$ \\
\hline Extractive sector ${ }^{\mathrm{c}}$ & -0.01 & -0.01 \\
\hline Transforming sector ${ }^{\mathrm{c}}$ & $0.20 * *$ & $0.20 * *$ \\
\hline Business services sector ${ }^{\mathrm{c}}$ & $0.05^{*}$ & $0.05^{*}$ \\
\hline GNI LOG & 0.02 & 0.02 \\
\hline
\end{tabular}

Notes: *significant at $\mathrm{p}<0.05 ; * *$ significant at $\mathrm{p}<0.01$.

aMiddle East and North Africa $=1$, Rest of the world $=0$, and ${ }^{\mathrm{c}}$ customer oriented sector as the reference group.

Hypothesis 3 predicted less innovation for female entrepreneurs in the MENA region as compared to their counterparts in the rest of the world. Interestingly, contrary to our prediction, the results indicated that female entrepreneurs in the MENA region are more innovative than female entrepreneurs in the rest of the world $(\beta=0.20$, $p$-value $<0.05)$. This result has been presented in Table 3 .

Hypothesis 4 hypothesised that female entrepreneurs in the MENA region are less ambitious toward growth, as compared to the female entrepreneurs in the rest of the world. According to Table 2, this hypothesis was not supported, with the results indicating that the benefit of female entrepreneurs from their innovation toward growth is not determined by regional differences in our sample. 
Table 3 Innovation affected by region

\begin{tabular}{lc}
\hline & Coefficients \\
\hline Region ${ }^{\mathrm{a}}$ & $0.20^{* *}$ \\
Self-efficacy & 0.000 \\
Age & $-0.001^{* *}$ \\
Role modelling & $0.02^{* *}$ \\
Education & $0.002^{* *}$ \\
Risk-willingness & $0.01^{* *}$ \\
Opportunity alertness & $0.03^{* *}$ \\
Household size & $-0.005^{* *}$ \\
Log firm age & $-0.05^{* *}$ \\
Log firm size & 0.006 \\
Extractive sector & $-0.05^{* *}$ \\
Transforming sector & $0.01^{*}$ \\
Business services sector & $-0.02^{* *}$ \\
GNI LOG & $0.01^{*}$ \\
\hline
\end{tabular}

Notes: *significant at $\mathrm{p}<0.05 ; * *$ significant at $\mathrm{p}<0.01$.

${ }^{\mathrm{a}}$ Middle East and North Africa $=1$ and rest of the world $=0,{ }^{\mathrm{c}}$ customer oriented sector as the reference group.

\section{Discussion and conclusions}

The motivation for the current research comes from four key findings in entrepreneurship research. First, some studies in entrepreneurship domain have shown that innovation has a significant positive effect on growth and performance of the firms (e.g., Cheraghi et al., 2014). Second, there are some studies highlighting the lower growth expectations of the female entrepreneurs as compared to the men (e.g., Davis and Shaver, 2012). Third, it has been highlighted that the innovation and growth of women owned businesses is strictly related to the context in which they operate (Sequeira et al., 2016). Fourth, it has been suggested that women in the MENA regions face fundamental constraints in their entrepreneurial activity, growth and performance (Bahramitash and Esfahani, 2016). Taking to account these earlier findings, three important questions remain: first, does innovation level of women-owned firms in the MENA region differ from those owned by the women in the rest of the world? Second, does growth ambition of women-owned firms in the MENA region differ from those owned by the women in the rest of the world? Third, as compared to the female entrepreneurs in the rest of the world, do the female entrepreneurs in the MENA region benefit from their innovation toward growth differently from those elsewhere?

The aim of the current study was to answer the above three questions and to investigate the regional differences in female entrepreneurs' innovation and expected growth from innovation between the MENA region and the rest of the world. Data analysis using a representative sample of world female entrepreneurs indicated no difference between growth ambitions of female entrepreneurs in the MENA as compared to their counterparts in the rest of the world. Results also suggest that there is no 
difference in terms of benefiting from innovation toward growth among the MENA female entrepreneurs as compared to the rest of the world. Contrary to expectations, female entrepreneurs in the MENA region were more innovative than the other female entrepreneurs around the world.

The higher level of innovation among the MENA female entrepreneurs as compared to their counterparts in the rest of the world may be due to low competition intensity in the MENA region that helps the entrepreneurs import innovations and expect longer lifecycle for their innovations. This can also be due to the stages of the development of the economies so that the MENA region countries are mostly at their first stage of the development and belong to the factor driven stage that are characterised by cheap labour and factors of production (Porter et al., 2008) which can balance a part of institutional inefficiencies and lack of resources for innovation. It is also necessary to look at family dynamics in the MENA region. By their cultural tendencies, the female entrepreneurs of this region value marriage (Inglehart and Welzel, 2010) and this is important because research shows that married women are more innovative and growth oriented (Davis and Shaver, 2012). Higher level of confidence in innovation in traditional cultures also can be another explanation for higher level of innovation in the MENA region. Research shows that in the countries with traditional cultures such as the MENA countries, confidence in innovation is higher than the countries with secular cultures (Ashourizadeh et al., 2014).

Although the above explanations can help in better understanding of innovation among the MENA female entrepreneurs as compared to their peers in rest of the world, to gain a deeper understanding, a more detailed cross-regional investigation seems necessary. Additionally, there are some structural differences within the MENA region countries in terms of stability, corruption level, GDP and other economic factors. For example, in the MENA region, despite existence of some similarities in the institutional context, Gulf Council Countries (GCC Group) are different than the rest of the countries in terms of political stability, income per capita, economic openness and economic freedom which can affect the overall innovativeness level of female entrepreneurs because these conditions can ease the innovation in the products and processes. These differences and their possible effects on innovation can be another area of inquiry by future researchers.

\section{Acknowledgements}

1 The authors would like to express their deep gratitude to the guest editor Professor Thomas Schøtt and anonymous reviewers for their valuable comments on the initial draft of this paper.

2 The early draft of this paper was developed in a workshop on researching entrepreneurship using data of Global Entrepreneurship Monitor held on 4 October 2018, at Yeditepe University, Istanbul. Hereby, the authors would like to express their great appreciation to Professor Emine Esra Karadeniz and Yeditepe University for their hospitality.

3 Data of this research has been collected by Global Entrepreneurship Monitor. The responsibility of analyses remains to the authors. 


\section{References}

Aeeni, Z., Motavaseli, M., Sakhdari, K. and Saeedikiya, M. (2019) 'Extending the potential of Baumol's entrepreneurial allocation theory', Journal of Entrepreneurship in Emerging Economies, Vol. 11, No. 3, pp.416-435.

Ahmad, S.Z. (2011) 'Evidence of the characteristics of women entrepreneurs in the Kingdom of Saudi Arabia: an empirical investigation', International Journal of Gender and Entrepreneurship, Vol. 3, No. 2, pp.123-143.

Ashourizadeh, S., Chavoushi, Z.H. and Schøtt, T. (2014) 'People's confidence in innovation: a component of the entrepreneurial mindset, embedded in gender and culture, affecting entrepreneurial intention', International Journal of Entrepreneurship and Small Business, Vol. 23, Nos. 1-2, pp.235-251.

Bahramitash, R. and Esfahani, H.S. (2016) 'Women's economic role in the MENA region: growth and equality through female-owned SMEs', in Political and Socio-Economic Change in the Middle East and North Africa, pp.15-190, Palgrave Macmillan, New York.

Bastian, B.L., Sidani, Y.M. and El Amine, Y. (2018) 'Women entrepreneurship in the Middle East and North Africa: a review of knowledge areas and research gaps', Gender in Management: An International Journal, Vol. 33, No. 1, pp.14-29.

Belwal, S., Belwal, R. and Saidi, F.A. (2014) 'Characteristics, motivations, and challenges of women entrepreneurs in Oman's Al-Dhahira region', Journal of Middle East Women's Studies, Vol. 10, No. 2, pp.135-151.

Brixiová, Z. and Kangoye, T. (2016) 'Gender and constraints to entrepreneurship in Africa: new evidence from Swaziland', Journal of Business Venturing Insights, Vol. 5, No. C, pp.1-8.

Bulanova, O., Isaksen, E.J. and Kolvereid, L. (2016) 'Growth aspirations among women entrepreneurs in high growth firms', Baltic Journal of Management, Vol. 11, No. 2, pp.187-206.

Castaño, M.S., Méndez, M.T. and Galindo, M.Á. (2016) 'Innovation, internationalization and business-growth expectations among entrepreneurs in the services sector', Journal of Business Research, Vol. 69, No. 5, pp.1690-1695.

Cheraghi, M., Setti, Z. and Schøtt, T. (2014) 'Growth-expectations among women entrepreneurs: embedded in networks and culture in Algeria, Morocco, Tunisia and in Belgium and France', International Journal of Entrepreneurship and Small Business, Vol. 23, Nos. 1-2, pp.191-212.

Claude-Gaudillat, V. and Quélin, B.V. (2006) 'Innovation, new market and governance choices of entry: the internet brokerage market case', Industry and Innovation, Vol. 13, No. 2, pp.173-187.

Davidsson, P., Achtenhagen, L. and Naldi, L. (2010) 'Small firm growth', Foundations and Trends ${ }^{\circledR}$ in Entrepreneurship, Vol. 6, No. 2, pp.69-166.

Davis, A.E. and Shaver, K.G. (2012) 'Understanding gendered variations in business growth intentions across the life course', Entrepreneurship Theory and Practice, Vol. 36, No. 3, pp.495-512.

Filculescu, A. (2016) 'The heterogeneous landscape of innovation in female led-businesses - cross-country comparisons', Management \& Marketing, Vol. 11, No. 4, pp.610-623.

Gartner, W. and Liao, J. (2012) 'The effects of perceptions of risk, environmental uncertainty, and growth aspirations on new venture creation success', Small Business Economics, Vol. 39, No. 3, pp.703-712.

Hill, S. and Akhrass, E. (2018) 'Gender and entrepreneurship: recent developments in MENA (Middle East and North Africa)', in Entrepreneurship Ecosystem in the Middle East and North Africa (MENA), pp.305-325, Springer, Cham.

Inglehart, R. and Welzel, C. (2010) 'Changing mass priorities: the link between modernization and democracy', Perspectives on Politics, Vol. 8, No. 2, pp.551-567.

Kazemi, F. (2000) 'Gender, Islam, and politics', Social Research, Vol. 67, No. 2, pp.453-474. 
Liao, J. and Welsch, H. (2003) 'Social capital and entrepreneurial growth aspiration: a comparison of technology-and non-technology-based nascent entrepreneurs', The Journal of High Technology Management Research, Vol. 14, No. 1, pp.149-170.

Manolova, T.S., Carter, N.M., Manev, I.M. and Gyoshev, B.S. (2007) 'The differential effect of men and women entrepreneurs' human capital and networking on growth expectancies in Bulgaria', Entrepreneurship theory and Practice, Vol. 31, No. 3, pp.407-426.

Poggesi, S., Mari, M. and De Vita, L. (2016) 'What's new in female entrepreneurship research? Answers from the literature', International Entrepreneurship and Management Journal, Vol. 12, No. 3, pp.735-764.

Porter, M.E. (2008) Competitive Strategy: Techniques for Analyzing Industries and Competitors, Simon and Schuster, New York.

Porter, M.E., Delgado, M., Ketels, C. and Stern, S. (2008) 'Moving to a new global competitiveness index', The Global Competitiveness Report, pp.43-63.

Renzulli, L.A., Aldrich, H. and Moody, J. (2000) 'Family matters: gender, networks, and entrepreneurial outcomes', Social Forces, Vol. 79, No. 2, pp.523-546.

Roxas, H.B. and Chadee, D. (2011) 'A resource-based view of small export firms' social capital in a Southeast Asian country', Asian Academy of Management Journal, Vol. 16, No. 2, pp.1-28.

Sadeq, T. and Setti, Z. (2013) 'Effects of entrepreneurs' networking with national values on job growth expectations: a two-level analysis for the MENA region and Denmark', International Journal of Business and Globalisation, Vol. 11, No. 4, pp.443-459.

Saeedikiya, M., Aeeni, Z., Motavaseli, M. and Farsi, J.Y. (2017) 'The effect of innovation on growth aspirations and internationalization in firms: Africa compared to the Protestant Europe', in 20th International Scientific Conference - Enterprise and Competitive Environment, Brno, the Czech Republic, Conference Proceedings, pp.753-762.

Sequeira, J.M., Gibbs, S.R. and Juma, N.A. (2016) 'Factors contributing to women's venture success in developing countries: an exploratory analysis', Journal of Developmental Entrepreneurship, Vol. 21, No. 1, pp.1-31.

Tlaiss, H. and Kauser, S. (2011) 'Women in management in Lebanon', Women in Management Worldwide: Progress and Prospects, pp.299-315, Gower, Aldershot.

Watson, J. (2012) 'Networking: gender differences and the association with firm performance', International Small Business Journal, Vol. 30, No. 5, pp.536-558.

Welsh, D.H., Memili, E., Kaciak, E. and Al Sadoon, A. (2014) 'Saudi women entrepreneurs: a growing economic segment', Journal of Business Research, Vol. 67, No. 5, pp.758-762.

Williamson, O.E. (2000) 'The new institutional economics: taking stock, looking ahead', Journal of Economic Literature, Vol. 38, No. 3, pp.595-613.

Zampetakis, L.A., Bakatsaki, M., Kafetsios, K. and Moustakis, V.S. (2016) 'Sex differences in entrepreneurs' business growth intentions: an identity approach', Journal of Innovation and Entrepreneurship, Vol. 5, No. 1, p.29.

Zeidan, S. and Bahrami, S. (2011) 'Women entrepreneurship in GCC: a framework to address challenges and promote participation in a regional context', International Journal of Business and Social Science, Vol. 2, No. 14, pp.100-107. 